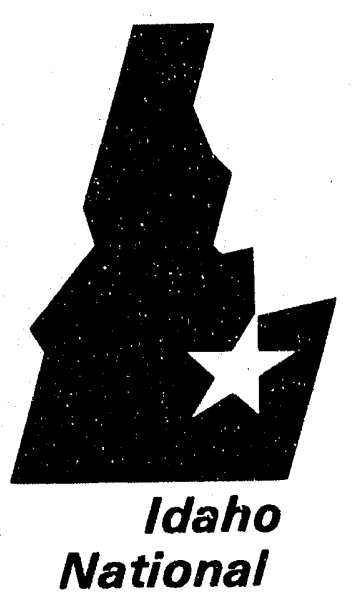

Engineering

Laboratory

Managed

by the U.S.

Department

of Energy
EGG-WTD-10610

February 1993

\section{Buried Waste Integrated Demonstration Strategy Plan}

K. M. Kostelnik

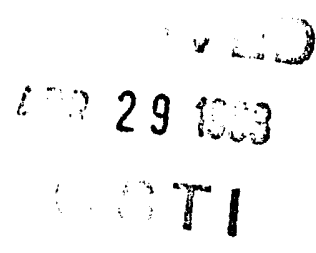

$\cos _{S} \operatorname{crg}_{\text {Idaho }}$

Work performed under DOE Contract No. DE-ACO7-761D01570 
This document contains new concepts or the author(s) interpretation of new calculations and/or measurements; accordingly, EG\&G Idaho, Inc. is required by the United States Government to include the following disclaimer:

\section{DISCLAIMER}

This report was prepared as an account of work sponsored by an agency of the United States Government. Neither the United States Government nor any agency thereof, nor any of their employees, makes any warranty, express or implied, of assumes any legal liability or responsibility for the accuracy, completeness, or usefulness of any information, apparatus, product or process disclosed, or represents that its use would not intringe privately owned rights. Reterences herein to any specific commercial product, process, or service by trade name, trademark, manufacturer, or otherwise, does not necessarily constitute or imply its endorsement, recommendation, or favoring by the United States Government or any agency thereof. The views and opinions of authors expressed herein do not necessarily state or reflect those of the United States Government or any agency thereof. 


\section{Buried Waste Integrated Demonstration Strategy Plan}

K. M. Kostelnik

Published February 1993

Idaho National Engineering Laboratory

EG\&G Idaho, Inc.

Idaho Falls, Idaho 83415

Prepared for the

U.S. Department of Energy

Office of Environmental Restoration and Waste Management

Under DOE Idaho Fleld Office

Contract DE-AC07-76ID01570 


\section{Buried Waste Integrated Demonstration Strategy Plan}

EGG-WTD-10610

Prepared by

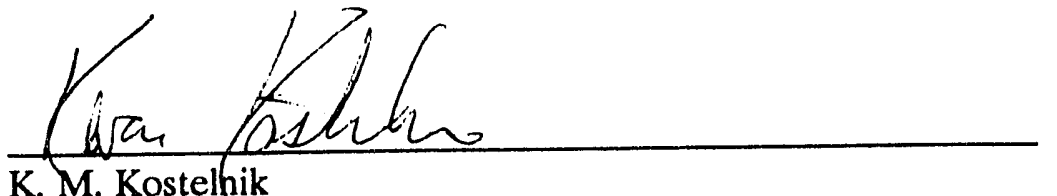

K. M. Kostelnik

BWID Project Manager

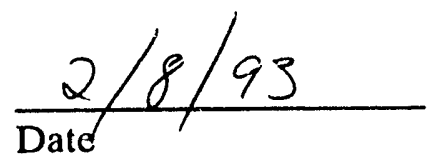

Reviewed by
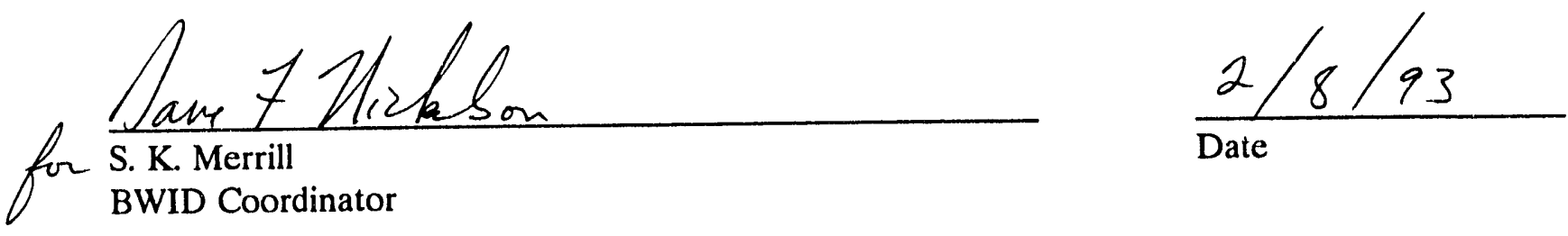


\begin{abstract}
The Buried Waste Integrated Demonstration (BWID) supports the applied research, development, demonstration, and evaluation of a suite of advanced technologies that form a comprehensive remediation system for the effective and efficient remediation of buried waste. These efforts are identified and coordinated in support of the U.S. Department of Energy (DOE), Environmental Restoration and Waste Management (ERWM) needs and objectives. The present focus of BWID is to support retrieval and ex situ treatment configuration options. Future activities will explore and support containment and stabilization efforts in addition to the retrieval/ex situ treatment options.

Long and short term strategies of the BWID are provided. Processes for identifying technological needs, screening candidate technologies for BWID applicability, researching technical issues, field demonstrating technologies, evaluating demonstration results to determine each technology's threshold of capability, and commercializing successfully demonstrated technologies for implementation for environmental restoration also are presented in this report.
\end{abstract}




\section{CONTENTS}

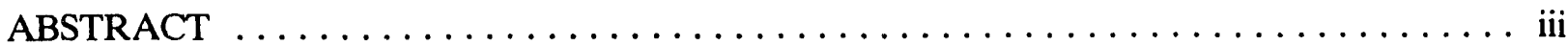

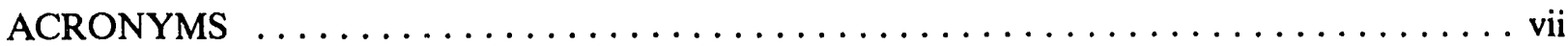

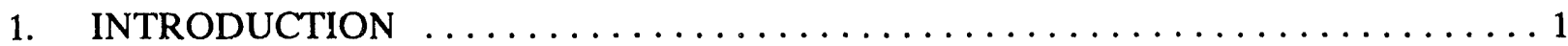

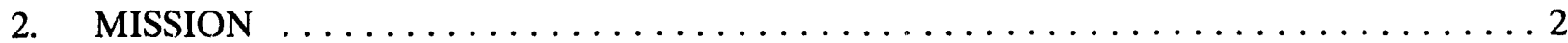

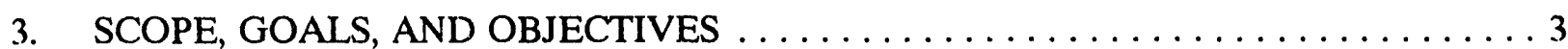

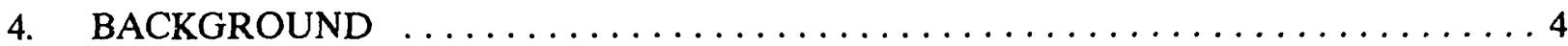

$4.1 \quad$ Buried Waste Problem $\ldots \ldots \ldots \ldots \ldots \ldots \ldots \ldots \ldots \ldots \ldots \ldots \ldots \ldots$

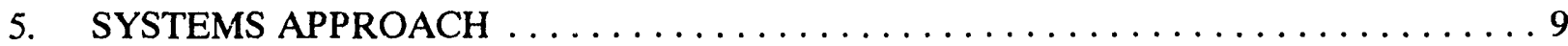

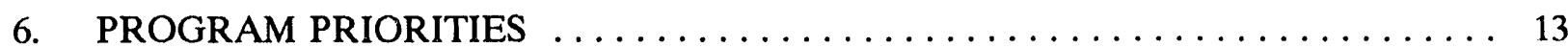

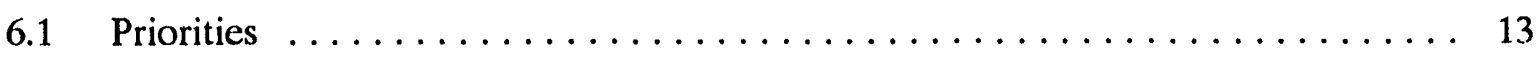

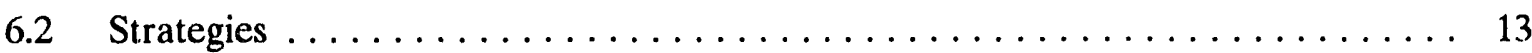

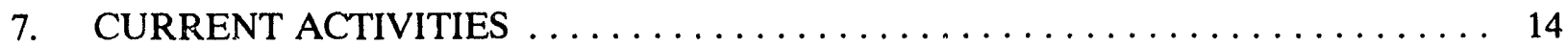

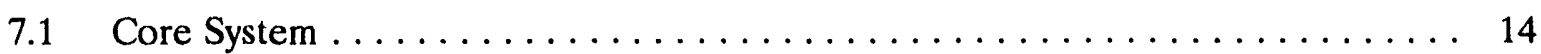

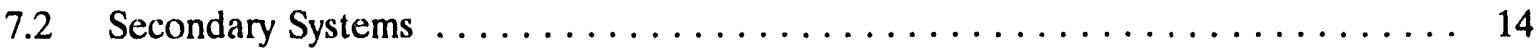

7.3 Research and Development Efforts $\ldots \ldots \ldots \ldots \ldots \ldots \ldots \ldots \ldots \ldots \ldots$

8. TECHNOLOGY COMMERCIALIZATION $\ldots \ldots \ldots \ldots \ldots \ldots \ldots \ldots \ldots$

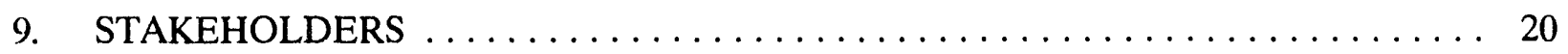

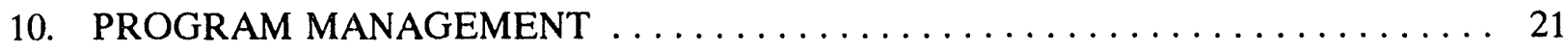

11. REFERENCES $\ldots \ldots \ldots \ldots \ldots \ldots \ldots \ldots \ldots \ldots \ldots \ldots \ldots \ldots \ldots \ldots \ldots \ldots \ldots \ldots \ldots \ldots, 23$

Appendix A-BWID Core System Technologies $\ldots \ldots \ldots \ldots \ldots \ldots \ldots \ldots \ldots \ldots \ldots$ A-1

Appendix B-BWID Secondary System Technologies .................... B-1

Appendix C-EWID Research and Development Technologies $\ldots \ldots \ldots \ldots \ldots \ldots \ldots$ C-1

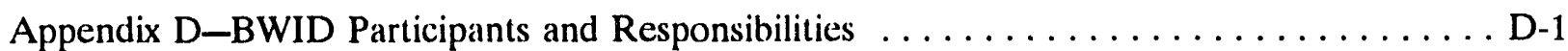




\section{FIGURES}

1. Barrels and wooden boxes stacked in INEL Pit 10 for disposal $(6 / 2 / 70) \ldots \ldots \ldots \ldots$

2. Unloading cardboard boxes of waste int’) INEL Trench II $(3 / 28 / 58) \ldots \ldots \ldots \ldots \ldots$

3. Example of materials routinely disposed of at DOE sites (simulated waste

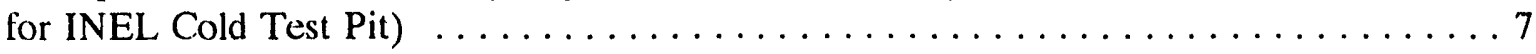

4. Large bulk waste disposal in INEL Pit 13 occurred in $1973 \ldots \ldots \ldots \ldots \ldots \ldots \ldots$

5. BWID is exploring four high-level systems for the remediation of buried waste. $\ldots \ldots 10$

6. Block diagram illustrating the subelements of the retrieve/ex situ treat

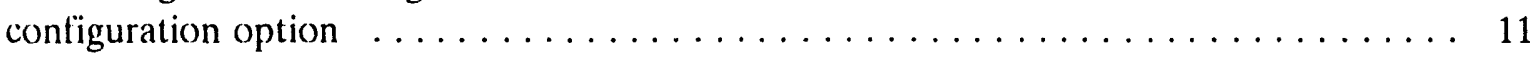

7. BWID's life-cycle WBS supports technology development for multiple

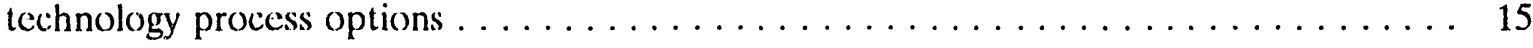

8. BWID's core system sponsors technology development within the retrieve/ex situ

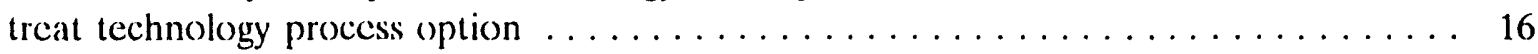

9. Conceptual drawing of the FY-93 BWID core system integrated demonstration at the

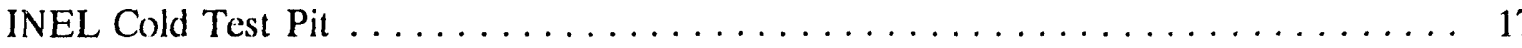

10. BWID organizational and management structure $\ldots \ldots \ldots \ldots \ldots \ldots \ldots \ldots \ldots \ldots$ 


\section{ACRONYMS}

BWID Buried Waste Integrated Demonstration

CERCLA Comprehensive Environmental Response, Compensation, and Liability Act

DOE U.S. Department of Energy

EPA Environmental Protection Agency

EPI Electro-pyrolysis, Inc.

ERWM Environmental Restoration and Waste Management

FY fiscal year

ID Integrated Demonstration

IDC Integrated Demonstration Coordinator

INEL Idaho National Engineering Laboratory

IP Integrated Program

MIT Massachusetts Institute of Technology

OTD Office of Technology Development

PNL Pacific Northwest Laboratory

PPG Program Planning Group

RCRA Resource Conservation and Recovery Act

RCS Remote Characterization System

RDDT\&E Research, Development, Demonstration, Testing, and Evaluation

RES Remote Excavation System

RI/FS Remedial Investigation/Feasibility Study

RWMC Radioactive Waste Management Complex

TPO Technical Program Officer

TRU transuranic 


\section{Buried Waste Integrated Demonstration Strategy Plan}

\section{INTRODUCTION}

The U.S. Department of Energy (DOE), Office of Technology Development (OTD) has initiated a comprehensive Research, Development, Demonstration, Testing, and Evaluation (RDDT\&E) plan. This effort encourages and promotes emerging remediation technologies that support DOE Office of Environmental Restoration and Waste Management (ERWM) objectives. Various technical issues and environmental needs have been identified by ERWM throughout the DOE complex. The nature of the DOE remediation problem has resulted in numerous opportunities for technology development. The OTD effort has heen organized to focus resources, through an assortment of Integrated Programs (IP) and Integrated Demonstrations (ID), that are technology and problem specific.

The Buried Waste Integrated Demonstration (BWID) project was organized at the Idaho National Engineering Laboratory (INEL) to support RDDT\&E of emerging technologies that offer promising solutions to the problems associated with the environmental restoration of buried waste. The BWID addresses difficult remediation problems associated with DOE complex-wide buried waste with particular focus on transuranic (TRU)-contaminated buried waste. A systems approach to problem characterization, need identification, and technology development that involves engineers and scientific expertise from throughout the DOE complex, universities, private sector, and international communities was established to advance the understanding of potential technologies for remediation of these buried wastes. 


\section{MISSION}

The BWID mission is to support development and demonstration of a suite of technologies that are integrated with commercially-available baseline technologies to form a comprehensive remediation system for the effective and efficient remediation of buried waste disposed of throughout the DOE complex. BWID will evaluate and validate demonstrated technologies and transfer this information and equipment to ERWM to support remediation planning and implementation.

BWID's measure of success will be determined by its contribution to improving the buried waste remediation process in terms of remediation salety, quality, schedule, and cost. 


\section{SCOPE, GOALS, AND OBJECTIVES}

The complexity and heterogeneity of buried waste associated with the DOE complex required considerable effort in identifying appropriate remediation schemes. Preliminary evaluations indicated that significant technological advancements are required to safely and cost effectively complete the remediation of this buried waste within the time frame defined by various Federal Facility Agreement and Consent Orders between the DOE, Environmental Protection Agency (EPA), and various host States. ${ }^{1,2,3}$

The scope of BWID is to support the buried waste remediation efforts of ERWM. Solutions to technology gaps identified in baseline remediation strategies will be sought. The near-term remediation schedules of ERWM will be supported through accelerated technology development efforts. Site specific issues associated with buried waste also will be supported by BWID.

The goal of BWID is to determine the threshold of capability for emerging technologies. Technologies will be identified, screened for applicability to the identified needs and requirements of ERWM, selected for demonstration, and evaluated based on prescribed performance objectives. This effort will determine implementability, effectiveness, potential schedule reduction, and cost savings associated with an emerging technology to shape remediation plans and implementation of the environmental restoration of buried waste.

A technical objective of the program is to establish the BWID as a technological solution for identified ERWM technological deficiencies as well as improve baseline remediation systems. Technologies that can potentially apply to buried waste remediation will be investigated to support the Remedial Investigation/Feasibility Study (RI/FS) process in accordance with the Comprehensive Environmental Response, Compensation, and Liability Act (CERCLA) and Resource Conservation and Recovery Act (RCRA) evaluation criteria.

Long term key objectives of the BWID are to improve environmental remediation processes, improve best management practices for buried waste, reduce personnel hazards of remediation activities, facilitate the development and commercialization of technologies to assist ERWM in ensuring the long term safety of the public and environment, reduce remediation costs, accelerate technology development, and ensure technology commercialization.

The tactics used by BWID to achieve these objectives include forming alliances within industry, DOE laboratories, universities, and Federal agencies to improve communication and the transfer of information on sponsored and demonstrated technologies; leveraging related activities with other IPs, IDs, ERWM, other government agencies, and private industry; and integrating field demonstrations. 


\section{BACKGROUND}

\subsection{Buried Waste Problem}

The amount of buried waste located throughout the DOE complex as of 1990 is estimated at approximately 2.1 million cubic meters. ${ }^{3}$ The DOE facilities where this waste is predominantly located are Hanford, Savannah River Site, INEL, Los Alamos National Laboratory, Oak Ridge National Laboratory (X-10), and Rocky Flats Plant. The wastes at these various sites have been buried or stored in several types of structures, including trenches, pits, buildings, storage pads, or other specific structures. Waste disposal activities at DOE sites were conducted in accordance with applicable regulations and laws and accepted engineering practices at the time. Figure 1 illustrates a typical stacked disposal pit at the INEL during 1970. Figure 2 illustrates a typical disposal trench at the INEL during 1958.

Approximately haif of all DOE buried waste was disposed of before 1970 in accordance with the regulations of that time. Disposal regulations at that time permitted the commingling of various lypes of waste [i.c., TRU, low-level radioactive (LLW), and hazardous]. As a result, much of the buricd waste throughout the DOE complex is presently believed to be contaminated with both hazardous and radioactive materials. DOE buried waste typically includes TRU-contaminated radioactive waste, LLW, hazardous waste per 40 CFR 261, greater-than-class-C (GTCC) waste per 10 CFR 61.55, mixed TRU waste, and mixed LLW. Interstitial soils are also believed to be contaminated as a result of these disposal practices, which significantly increases the volume of materials requiring remediation.

Typical buried waste includes construction and demolition materials (i.e., lumber, concrete blocks, steel plates, etc.), laboratory equipment (i.e., hoods, desks, tubing, glassware, etc.), process equipment (i.e., heat exchanger, valves, ion exchange resins, high efficiency particulate air filters, etc.), maintenance equipment (i.e., hand tools, cranes, oils and greases, etc.), and decontamination materials (i.e., paper, rags, plastic bags). Figure 3 illustrates the type of materials routinely disposed of in DOE burial grounds. This figure shows simulated waste being prepared for the INEL Cold Test Pit.

A variety of containers were used for the disposal of huried waste. Typical containers, used for waste shipment such as those used at the INEL, included steel drums (30, 40, and 55-gal), cardboard cartons, and wooden boxes (up to $105 \times 105$ in. $\times 214$ in.). Larger individual items were disposed of separately as loose trash (see Figure 4). Degradation of the waste containers is believed to have resulted in contamination of the immediately surrounding soil. Estimates of contaminated soils at the INEL are in the order of 8 million cubic feet. The waste and site characteristics of the INEL Radioactive Waste Management Complex (RWMC) are generally representative of other DOE buried waste sites. Therefore, remediation technology demonstrations performed at the INEL should be transferable for potential applications at other DOE buried waste sites. 


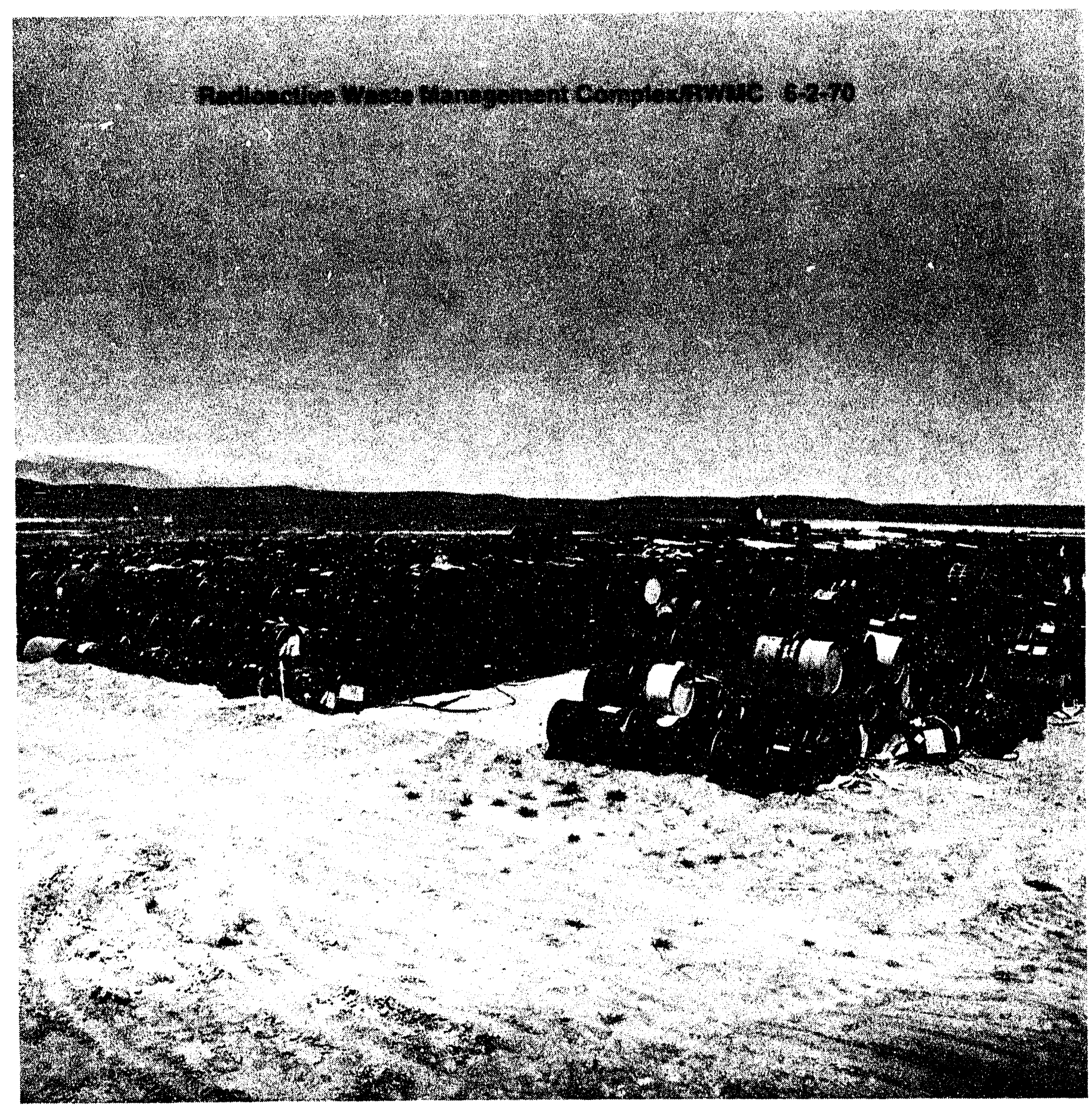

Figure 1. Barrels and wooden boxes stacked in INEL Pit 10 for disposal (6/2/70). 
Radioactive Waste Management Complex/RWMC $\quad 3-28-58$

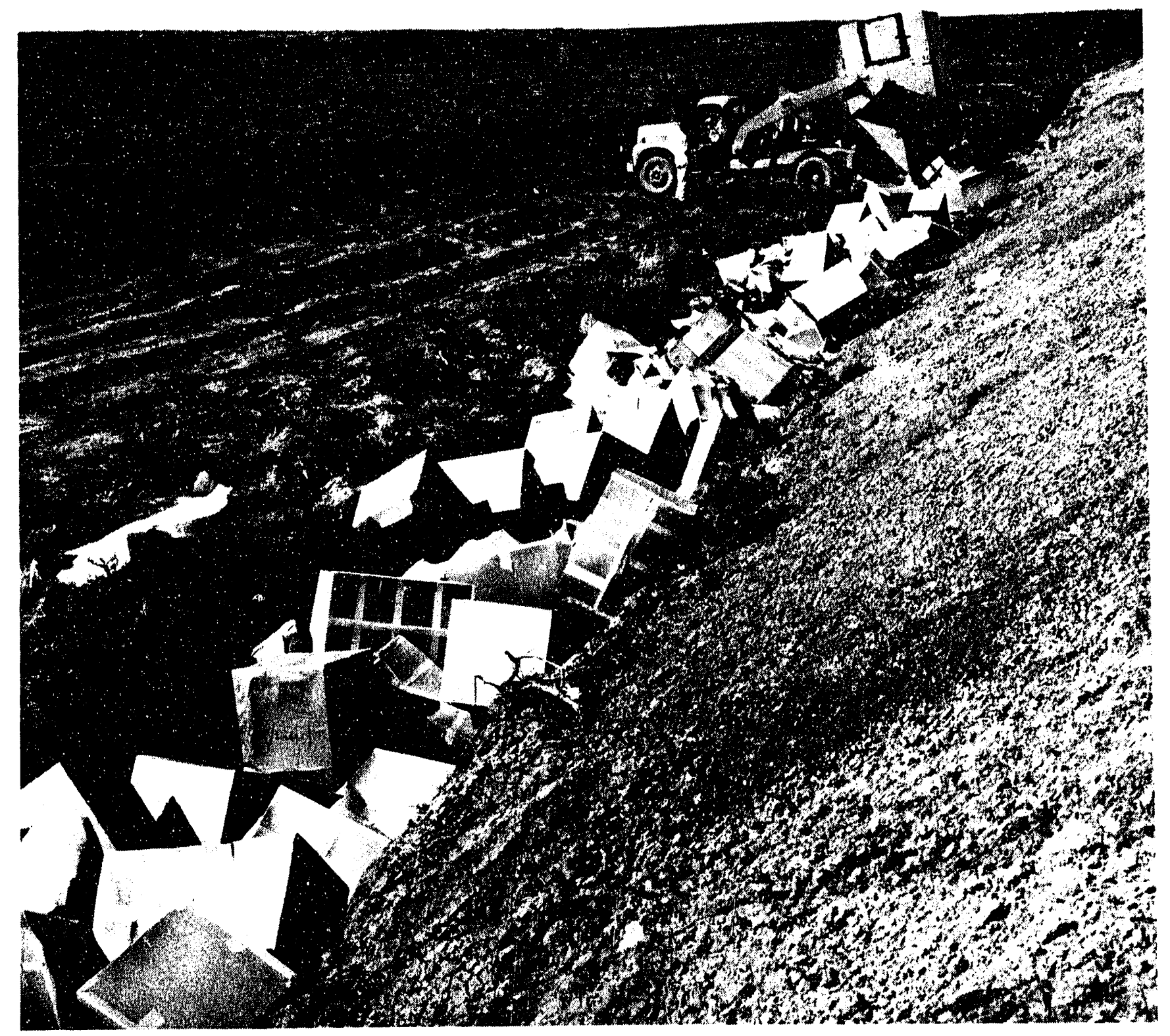

Figure 2. Unloading cardboard boxes of waste into INEL Trench II (3/28/58). 


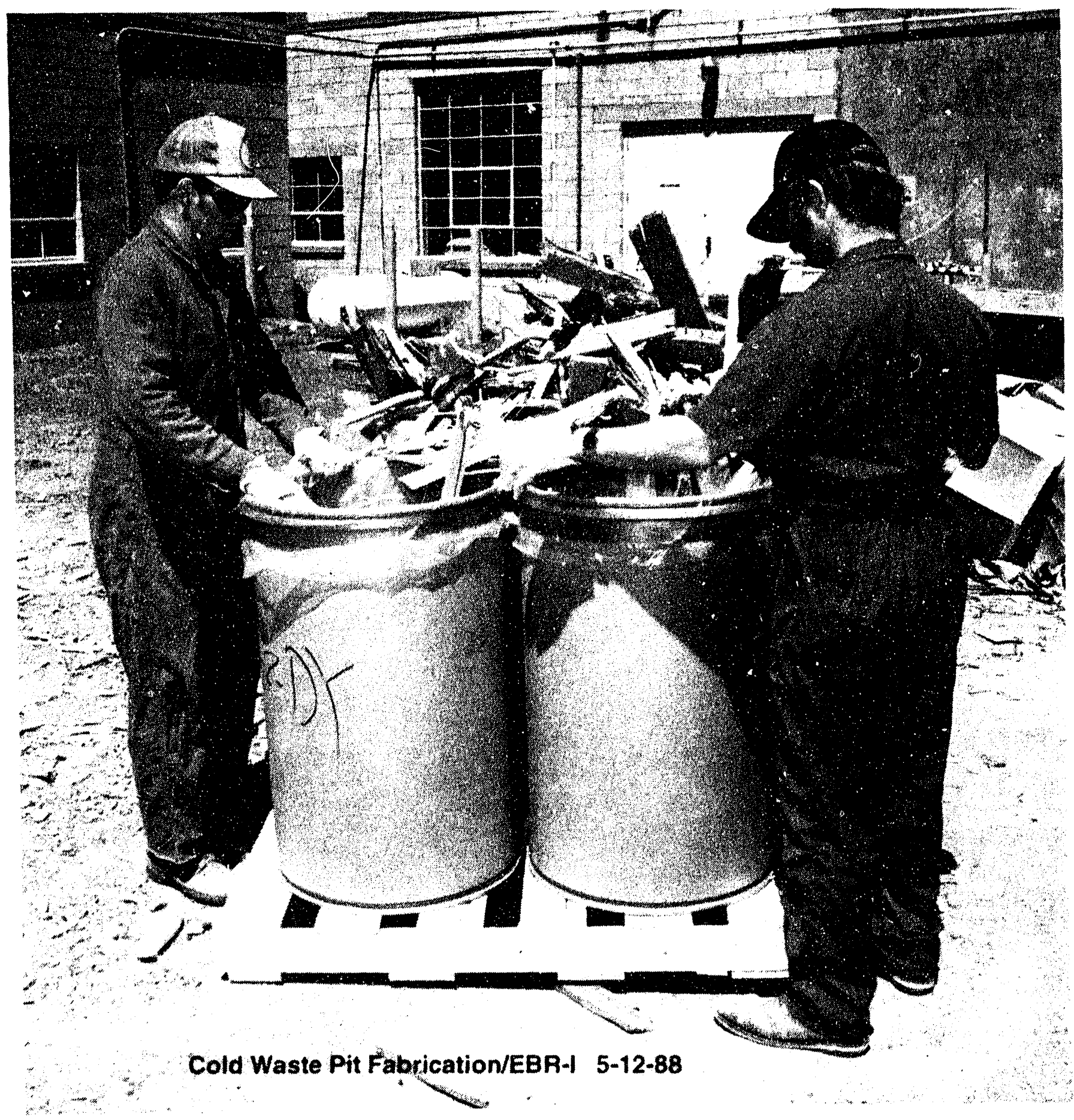

Figure 3. Example of materials routincly disposed of at DOE sites (simulated waste for INEL Cold Test Pit). 
Radioactive Waste Management Complex/RWMC $\quad$ 7-19-73

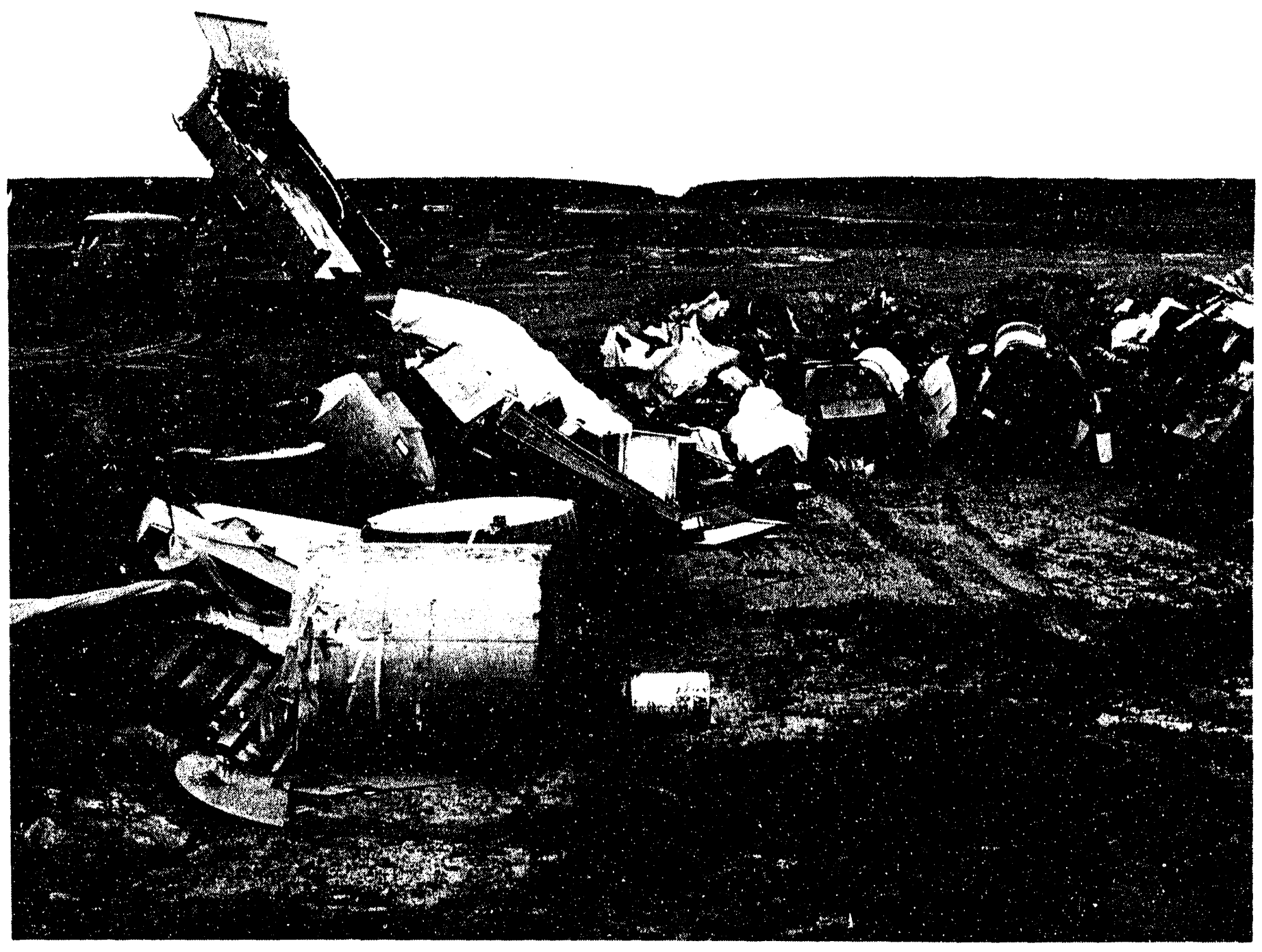

Figure 4. Large bulk waste disposal in INEL Pit 13 occurred in 1973. 


\section{SYSTEMS APPROACH}

Significant remediation challenges are presented for buried waste, particularly the pre-1970 buried TRU-contaminated waste. The DOE Office of Environmental Restoration (ER) is committed to resolving the issues resulting from past disposal practices. The OTD supports these efforts to ensure that appropriate technological solutions are available to accomplish the selected remediation objectives. To address these issues and identify technological solutions for remediation deficiencies, the OTD initiated BWID at the INEL.

BWID is exploring four high-level systems for the remediation of buried waste. These systems are illustrated in Figure 5. The four systems illustrated in this figure, beginning at the bottom of the figure and moving to the top, include the characterization/retrieve/ex situ treat system, characterization/in situ treat/retrieve system, characterization/in situ treat/monitor system, and characterization/contain/stabilize/monitor system. Each element or technology process within a system requires specific input and output. Each technology process is integrated with and dependent on its surrounding processes. These processes must perform to their expected levels for the overall system to be successful in achieving its remediation objectives.

The characterization/retricval/ex situ treatment system involves exhuming and subsequently treating the retrieved waste. Figure 6 is a block diagram illustrating the various steps necessary to accomplish this option. A comprehensive discussion of this configuration option is found in the INEL Operable Unit 7-13 Configuration Option Report. ${ }^{4}$ Characterization efforts are required to permit a safe exhumation process. Retrieved waste and soil needs to be packaged and transported to a treatment facility. Pretreatment, such as size reduction and metal sorting, may be required. Waste streams will eventually need to be treated. To date the emphasis has been high-temperature thermal treatments, but treatment techniques such as biological and chemical are also being investigated. Final waste forms will be assayed to determine disposal requirements. Packaging and ultimate disposal complete this system option.

The primary objective of the characterization/in situ treatment/retrieval system is to utilize in situ treatment processes to minimize the potential spread of contamination before and during buried waste retrieval. The combination of in situ treatment and subsequent retrieval provides significantly reduced potential for contamination spread versus the retrieval of untreated waste. The FY-93 BWID effort involves a review of various existing program/project activities that are underway within the DOE complex, at other government agencies, and in the private sector. Outyear efforts will explore the field deployment of technologies for buried waste applications.

The objective of the characterization/in situ treatment/monitoring system is to adequately in situ treat radiological and/or hazardous buried waste so that the subsequent waste form can be left in place. The performance characteristics of the treated waste must provide for the destruction of hazardous waste and immobilization of radiological waste constituents in both waste and interstitial soils. This treatment must represent a "permanent" solution in which long-term hazardous and radiological releases to groundwater, surface soils, or air are reduced to acceptable levels. In addition to TRU and nonTRU radionuclides, the system must include identification, treatment, and monitoring capabilities for hazardous organics and metals. This may be done with a single process or with individual treatment techniques that address the various aspects of waste. The FY-93 BWID effort 


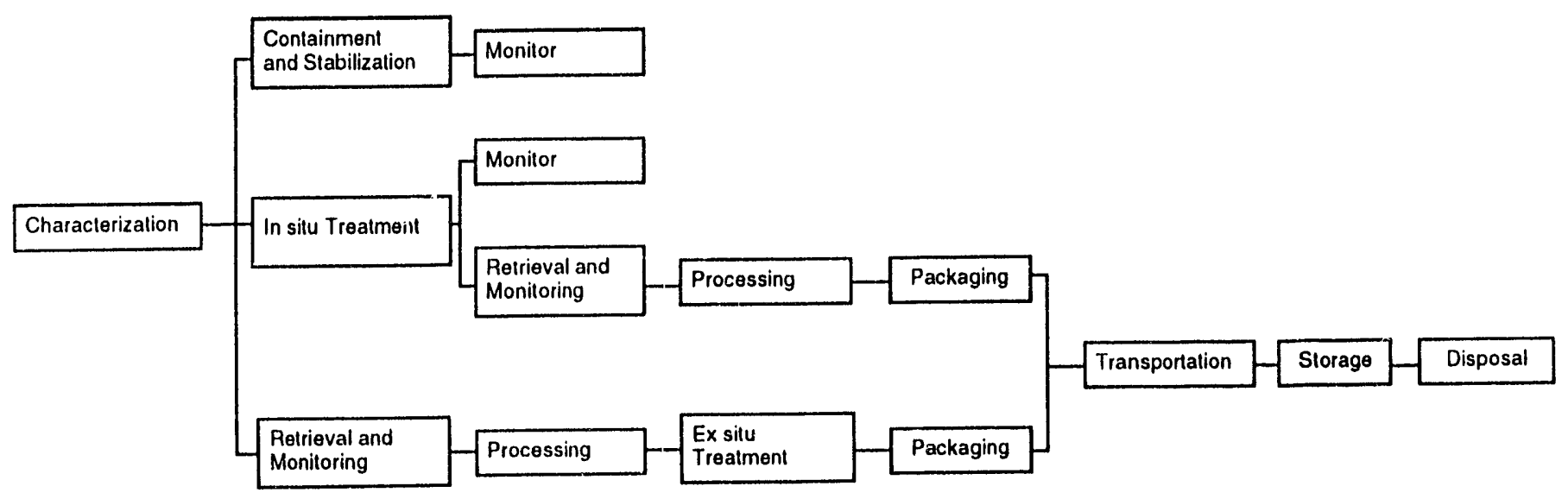

R92 1644

Figure 5. BWID is exploring four high-level systems for the remediation of buried waste. 


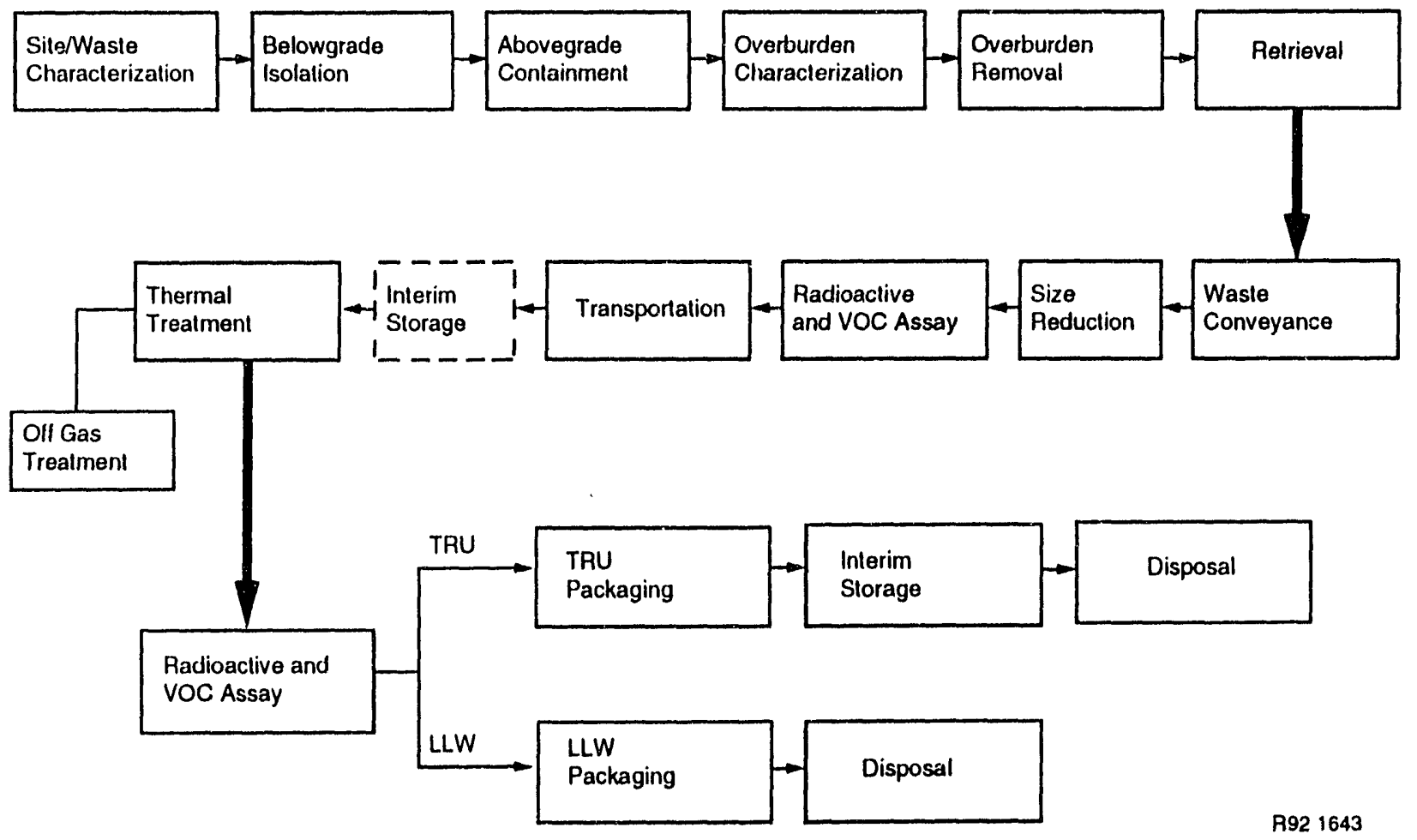

Figure 6. Block diagram illustrating the subelements of the retrieve/ex situ treat configuration option. 
involves a review of existing program/project activities underway within the DOE complex, at other government agencies, and in the private sector. Outyear efforts will explore the field deployment of technologies for buried waste applications.

The objective of the FY-93 project activity addressing characterization/contain/stabilize/monitor system is to review various existing program/project activities underway within the DOE complex, at other government agencies, and in the private sector. Engineered barriers that retard and prevent radionuclide and hazardous substance migration from ncar-surface buried waste sources will be identified and evaluated for appropriateness for future demonstration. Primary areas of applied research, development, and demonstration will be groundwater intrusion into buried waste and potential migration of contaminated waste out of the waste seam. The FY-93 activities will be coordinated with the Mixed Waste Landfill ID, In Situ Remediation IP, and Underground Storage Tank ID. Outyear efforts will explore the field deployment of technologies for buried waste applications. 


\section{PROGRAM PRIORITIES}

\subsection{Priorities}

Each technology process option illustrated in Figure 5 offers opportunities for technology development. The priority for BWID is to support technology development for those process options in which no baseline technology presently exists. Therefore, filling technological gaps is the first program priority for BWID.

The characterization/retrieve/ex situ treatment option is the highest priority option in which technological gaps have been identified. Solving the technology gaps associated with the remaining three configuration options shown in Figure 5 are the next program priority. During FY-93, the BWID will continue to collaborate with ERWM to define these options and their associated technological gaps.

The third program priority is to enhance baseline technologies to improve the environmental remediation capabilities of the DOE.

\subsection{Strategies}

Throughout these programmatic priorities lie the BWID implementation strategies. These strategies will assist BWID in meeting its objectives. The BWID will accomplish its objectives by involving technical participants and technology sponsors from throughout the DOE complex, private industry, and universities. Collaboration with other OTD-sponsored IDs and IPs, private sector participants, and universities is also highly encouraged. Collaborative efforts have been implemented and are key to reducing duplication of effort, accelerating technology development, and leveraging DOE funding.

Technologies demonstrating their viability for BWID-sponsorship will be reviewed on their appropriateness to the identified needs, integration into the defined system options, collaboration with the private sector, and schedule for field demonstration. Technical evaluations will utilize specific performance indicators to estimate a proposed technology's effectiveness, implementability, and lifecycle cost. 


\section{CURRENT ACTIVITIES}

The BWID FY-93 program was built from the successful FY-92 program. Details of FY-92 demonstration activities and programmatic achievements are found in the BWID FY-92 Close Out Report. $^{6}$

The FY-93 program builds on the systems approach previously described. Figure 7 illustrates the BWID Life-cycle Work Breakdown Structure (WBS). This WBS presents three distinct efforts of technology development. These efforts include the FY-93 core system of characterization, retrieval, and ex situ treatment; the secondary systems that include characterization and in situ treatment, and characterization, containment, and stabilization; and buried waste applied research and development efforts. The major emphasis of the FY-93 BWID program is the core system. This system is field deployment oriented while the remaining program efforts are developmental and lead to field deployment in outyears.

\subsection{Core System}

The BWID FY-93 core system is focused on the characterization/retrieve/ex situ treat technology process option. The specific system requirements are described in the INEL Operable Unit 7-13 Configuration Option Report. ${ }^{4}$ Technologies were selected for the FY-93 core system based on these specific requirements.

The FY-93 core system involves technologies that satisfy the requirements of the first six subelements of the characterization/retrieve/ex situ treat technology process option illustrated in Figure 6 as well as the thermal treatment subelement. Appendix A provides a brief description of each technology involved.

A major aspect of the FY-93 core system is focused on field deployment. These activities will culminate in an FY-93 core system demonstration at the INEL Cold Test Pit during the summer of 1993. This demonstration will be comprised of multiple technologies that are integrated for field demonstration. These activities have been selected to address specific technical issues remaining for the characterization through retrieval components of the characterization/retrieve/ex situ treatment technology process option for remediating TRU-contaminated waste. Figure 8 lists the technologies within the characterization/retrieve/ex situ treatment option that make up the FY-93 core system demonstration. Figure 9 is a conceptual drawing highlighting several key technologies involved in the FY-9.3 core system demonstration. Elements within this illustration are the remote characterization system, remote excavation system, contamination control unit, and rapid monitoring unit.

The BWID FY-93 Deployment Plan ${ }^{7}$ provides a detailed description, schedules, and other logistical information on each of the various technologies involved in the FY-93 core system demonstration.

\subsection{Secondary Systems}

Two technology process options are supported within the FY-93 BWID secondary systems. These options include in situ treatment and contain and stabilize. The development and 


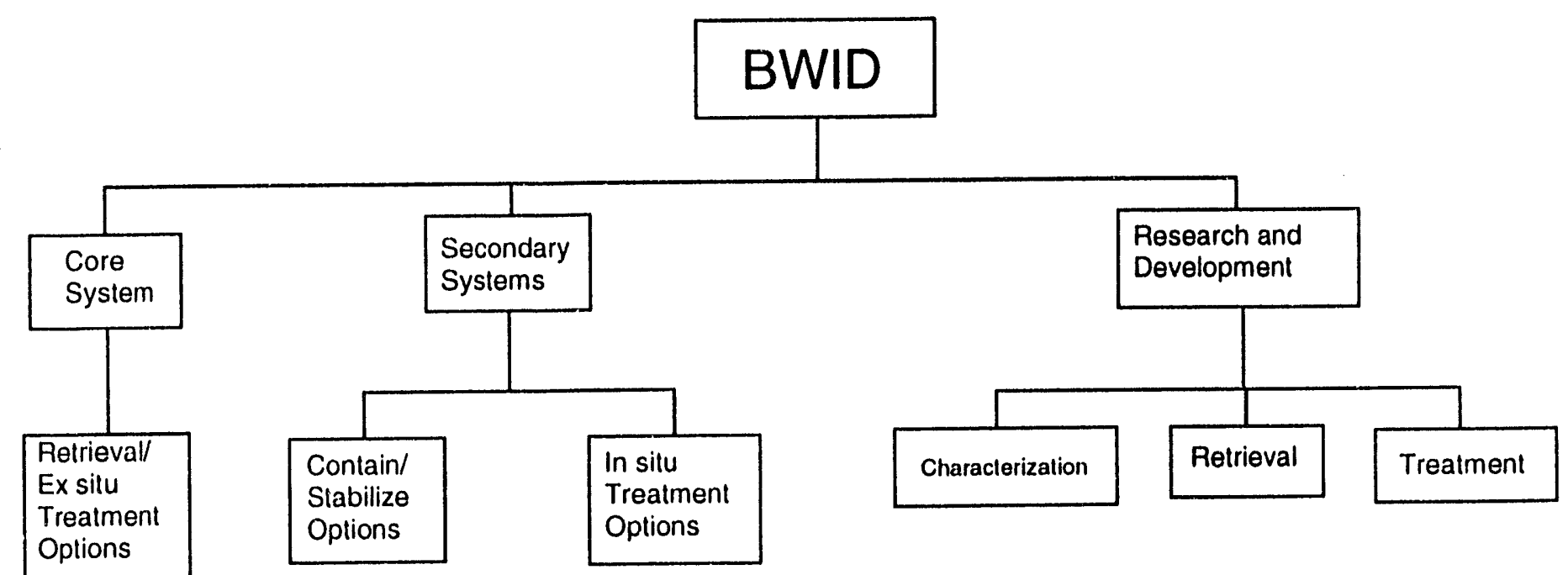

Figure 7. BWID's life-cycle WBS supports technology development for multiple technology process options. 


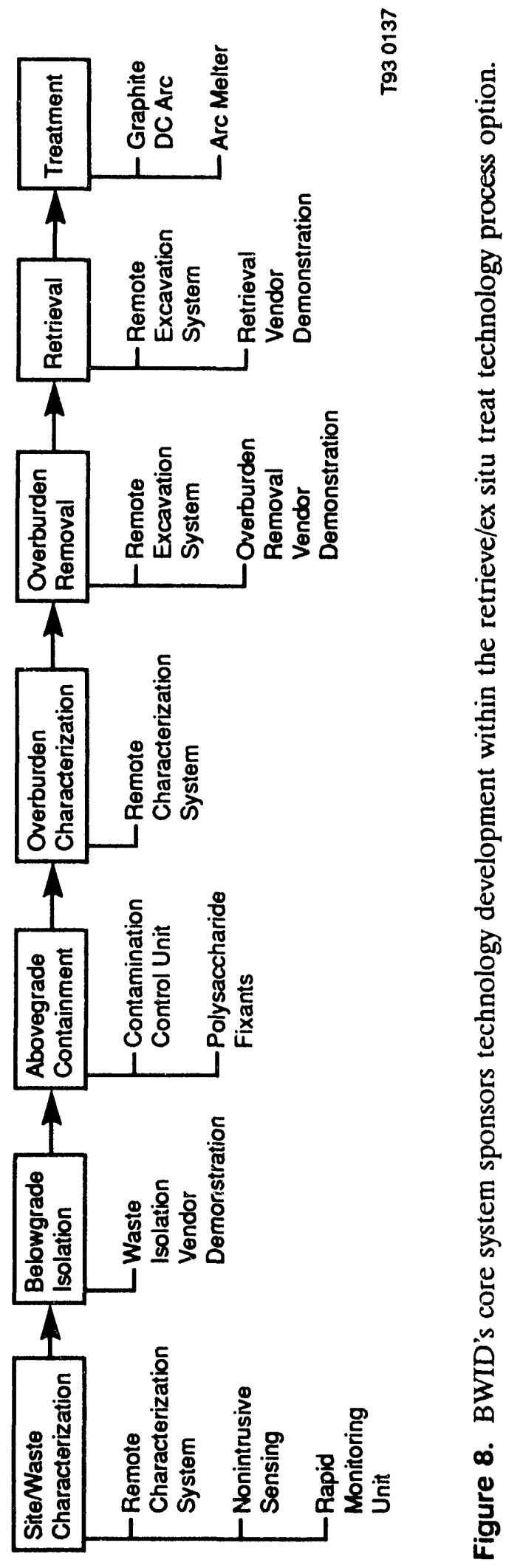




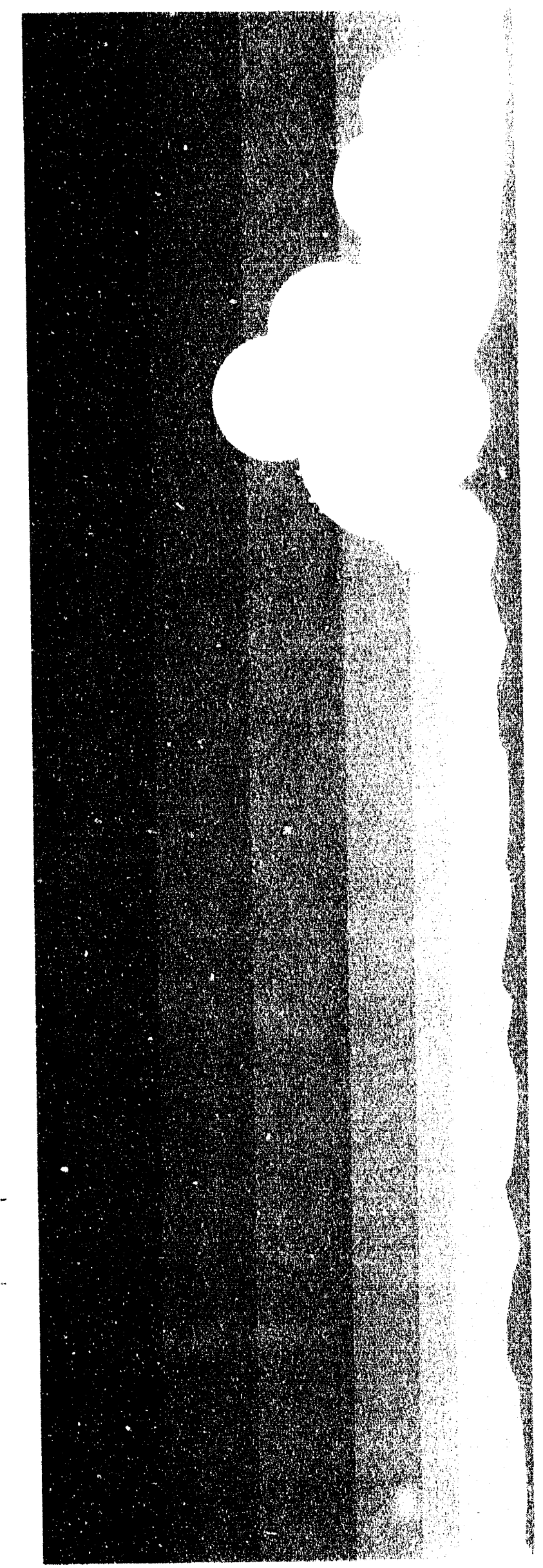

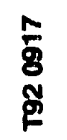

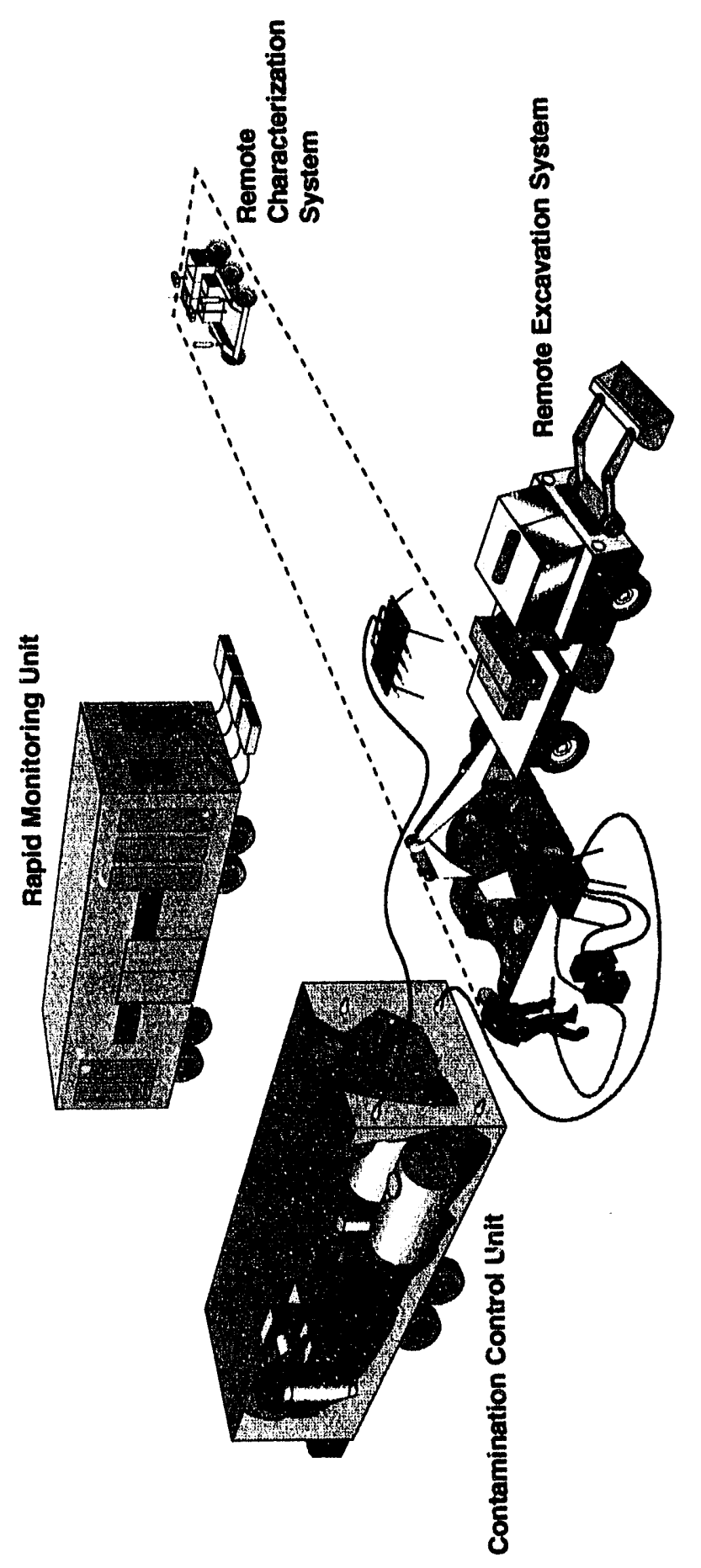

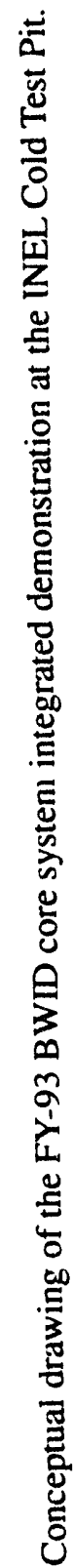

온 
demonstration of technoiogies that satisfy the requirements of these two system options for buried waste remediation are important objectives of BWID. However, during FY-93 these options are secondary efforts for the BWID program with limited development and demonstration supported by BWIL funding. The majority of the development efforts supporting these two options is presently being provided by other OTD IPs. It is envisioned that as these developing technologies mature within the IPs they will be transferred into the BWID program and support field deployment for demonstration and evaluation as related to buried waste remediation applications.

Appendix B provides a brief description of the technologies sponsored by the BWID in these two options. Selected technologies being developed by IPs that also could support these options and potentialiy be demonstrated by BWID in outyears are also described.

\subsection{Research and Development Efforts}

The third element of BWID WBS presents the applied research and development activities. This element involves the technologies that have been determined to apply, but their maturity requires additional development. The majority of support and funding for these development efforts is and alway; will be through other OTD IPs. Again, as with the BWID secondary systems, it is envisioned that is developing technologies mature within IPs they will be transferred into the BWID program for field demonstration and evaluation as related to buried waste remediation applications.

Presently, IPs do not exist or are not fully funded in all the technical areas dicemed critical to BWID. Techinologies requiring developmental support in those areas that are outside the realm of the existing IPs have been identified by BWID in FY-93. BWID developmental support for these technologies was provided by this research and development effort. Appendix $\mathrm{C}$ provides a brief descriptic 1 of the various technologies sponsored by the BWID research and development effort. Selected research and development being sponsored by IPs that could potentially satisfy BWID requirements in outyears are also described. 


\section{TECHNOLOGY COMMERCIALIZATION}

Many technological, institutional, and regulatory lactors can inhibit the use of innovative technologies for environmental remediation efforts. Overcoming these obstacles, improving the mechanisms for innovative technology use, and supporting the commercialization of technologies will expedite remediation efforts and provide cost savings to DOE.

BWID is committed to overcoming these barriers and fostering the use of innovative technologies for application to buried waste remediation. Several approaches have been initiated by the BWID in FY-92 and FY-93 to accomplish its technology transfer objective. These initiatives are being coordinated in conjunction with the OTD Technology Integration Branch and its procedures.

To improve the internal transfer of technologies within the DOE, the end-user of innovative technologies (i.e., ERWM Operable Unit Managers) must be aware of these technologies as soon as possible to permit proper planning for integration and subsequent use in remediation actions. BWID has recognized this situation and has structured its Program Planning Group to include endusers, customers, and regulators. The user representatives are thereby not only prepared to deploy developed technologies but are key to identifying the program needs, direction, and priorities for future technology development areas. The Program Planning Group also includes an EPA representative, where regulatory concerns are addressed carlicr in the development stages to avoid delays in deployment.

The BWID works with private industry and universities to provide mutually beneficial conditions that promote cooperation and technology commercialization. BWID and the OTD Technology Integration Branch co-sponsored a FY-92 Technology Integration Workshop for private industry and universities to disseminate information about the BWID technology needs and to solicit potential technological solutions. The response for information and private sector participation was overwhelming. Interest in and subsequent requests for proposals issued in FY-93 by BWID have been eagerly responded to by participants of this workshop. Additional BWID workshops for FY-93 are being considered and involvement in DOE sponsored workshops is a priority activity in the commercialization strategy.

The primary integration mechanism for BWID to date has been contracting and collaborative arrangements as a result of Commerce Business Daily announcements. The resources of the INEL Office of Research and Technology Applications will be strategically used to improve and implement other technology transfer mechanisms. The additional mechanisms that will be explored are Cooperative Research and Development Agreements, Cost-sharing Agreements, Program Research and Development Announcements, Memorandum of Understanding, Small Business Innovation Research Programs, and licenses. These mechanisms have been described in the Buried Waste Integrated Demonstration Technology Integration Process Report. ${ }^{5}$ 


\section{STAKEHOLDERS}

Stakeholders in the BWID program include individuals and organizations with an interest in technologies being considered for development and application to remediation efforts for DOE buried waste sites. BWID stakeholders, which include the general public, public officials, interest groups, universities, private industry, Federal and State regulatory agencies, national laboratories, other government agencies (e.g., Department of Defense, U.S. Geological Survey, and EPA), DOE, and DOE contractors are diverse in opinion and perspective. Each stakeholder presents an opportunity for input to enhance technology development within the BWID.

The BWID recognizes the advantages of involving the public and other key stakeholders in the technology demonstration stages that precede environmental remediation deployment periods. Efforts to identify, inform, and involve stakeholders are an ongoing activity that achieve public and regulatory acceptance of BWID-sponsored technology development for the remediation of buried radioactive and hazardous buried waste.

The BWID will implement an outreach program during FY-93 to inform and involve identified stakeholders. These efforts will concentrate primarily on organizations local to the INEL region (i.e., southern and eastern Idaho). Secondary activities will be directed to other regions through existing IP, ID, and OTD outreach programs. This aggressive outreach effort will involve the necessary formats to accommodate the stakeholders being addressed. Media releases for BWID-sponsored technology demonstrations will be released throughout FY-93. Presentations to selected professional societies, civic organizations, universities, schools, and other interest groups will be encouraged. Existing efforts such as the INEL Public Affairs and Community Outreach Program and the INEL Speaker's Bureau will be used to deliver BWID information. DOE-sponsored workshops such as the Community Leaders and Public Involvement Workshops will be supported, and a BWID technology exhibition will be sponsored to highlight the FY-93 technology field demonstrations. 


\section{PROGRAM MANAGEMENT}

The program team will coordinate the activities of the BWID. An OTD Program Manager, a DOE Field Office Technical Program Manager, a lield contractor Integrated Demonstration Coordinator, a needs-driven Program Planning Group, and technology-oriented Technical Support Groups comprise this team. Figure 10 illustrates the organizational structure of this management team. Appendix D lists the responsibilities and interfaces of this management team.

BWID will operate in accordance with the intent of DOE Orders 4700.1, "Project Management System," 2250.1C, "Cost \& Schedule Control Systems Criteria," and 5480.19, "Conduct of Operations." All BWID-sponsored projects will comply with pertinent regulatory, environmental, health and safety, security, and quality assurance requirements. Compliance will be based upon DOE Orders, DOE Directives, and policies and procedures established by the responsible DOE subcontractor. The BWID Project Management Plan a provides additional information on the project management activities of the BWID program.

a. EG\&G Idaho, BWID Project Management Plan, WTD-92-(038, 1992. 


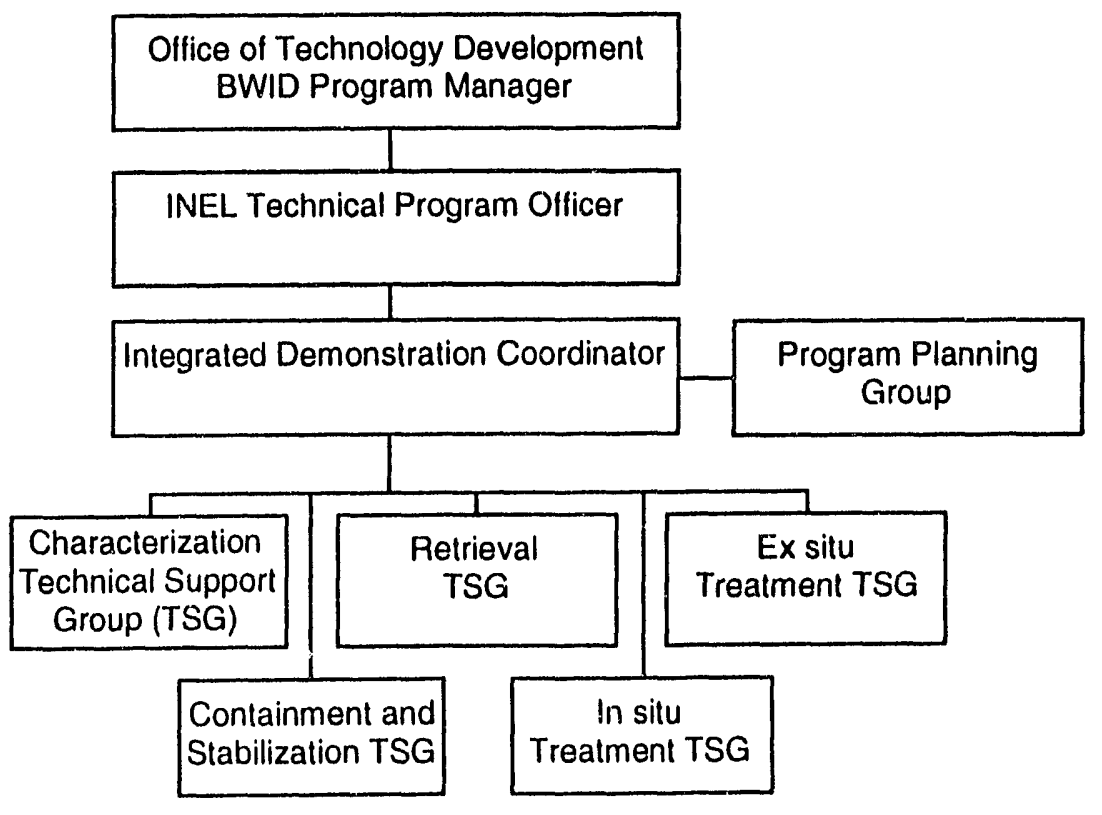

R92 1647

Figure 10. BWID organizational and management structure. 


\section{REFERENCES}

1. U.S. Department of Energy, Environmental Restoration and Waste Management Five-year Plan Fiscal Years 1993-1997, DOE/S-0090P, August 1991.

2. U.S. Department of Energy Idaho Field Office, Idaho National Engineering Laboratory Environmental Restoration Roadmap Document, Predecisional Draft, DOE/ID-10364, Revision 1, September 1992.

3. P. S. Kaal, G. M. Holter, S. M. K. Garrett, DOE Complex Buried Waste Characterization Assessment, PNL-8390, Pacific Northwest Laboratory, January 1993.

4. EG\&G Idaho, Inc., INEL Operable Unit 7-13 Configuration Option Report, EGG-WTD-10204, Revision 0, July 1992.

5. EG\&G Idaho, Inc., Buried Waste Integrated Demonstration Technology Integration Process Report, EGG-WTD-9928, April 1992.

6. EG\&G Idaho, Inc., BWID FY-92 Closeout Report, EGG-WTD-10612, February 1993.

7. EG\&G Idaho, Inc., BWID FY-93 Deployment Plan, EGG-WTD-10539, Draft, January 1993. 
Appendix A

BWID Core System Technologies 
- 


\section{Appendix A}

\section{BWID Core System Technologies}

Title:

TTP Number:

Remotc Characterization System (RCS)

Joint Participants: Guidance:

ID-332001

Robotic Technologies Integrated Program (IP), Industry, and Universities Provide a demonstration at the Idaho National Engineering Laboratory (INEL) Radioactive Waste Management Complex (RWMC) Cold Test Pit of the RCS, developed by the Buried Waste Robotics Program. This demonstration should involve an evaluation of the developed components such as the geophysical sensors (i.e., ground penetrating radar and magnetometers), low-signature vehicle, remote control systems, and global positioning system.

Title: $\quad$ Nonintrusive Sensing

TTP Number: $\quad$ AL-901201

Joint Participants: United States Geological Survey, Industry

Guidance:

Provide enhanced nonintrusive sensing techniques to aid in the characterization of remediation sites. Techniques should (1) improve techniques for mapping waste distribution and boundaries, (2) reduce uncertainty in the nonintrusive location methods of charactcrization of small targets and enable characterization of small targets, (3) improve methods of characterization of subsurface geohydrologic features and properties and (4) develop in situ methods of characterizing contaminants. Activities include time-domain Electromagnetics, tensor magnetic gradiometer, and borehole geophysical system.

Title: $\quad$ Remote Excavation System (RES) Demonstration

TTP Number: $\quad$ ID-332004

Joint Participants: Robotic Technologies IP, Industry, and Universities

Guidance: Provide a demonstration at the INEL RWMC Cold Test Pit of the RES developed by the Buried Waste Robotics Program. This demonstration should involve an evaluation of the developed components such as the remotized small excavation vehicle, remote control station, and end-effector teleoperations.

Title: $\quad$ Retricval Technologies

TTP Number: $\quad$ ID-132007

Joint Participants: Industry

Guidance:

Demonstrate state of the art overburden removal techniques and side burden stabilization techniques. The demonstrations will involve test plans and final analysis reports and will be completed in FY-93. The overburden removal demonstration will evaluate various overburden removal techniques for open air removal; the side burden stabilization demonstration will demonstrate several technologies to provide vertical walls for the pit boundaries so that the amount of side burden removed is minimized. 
Title:

Retrieval Demonstration

TTP Number:

ID-121203

Joint Participants:

Guidance:

Industry

Complete a cold test demonstration in simulated but typical buried waste of applicable excavator end effectors so that a combination of apparatus can be recommended for retricval. End effectors to be demonstrated might include backhoes, front shovels, and grapples with variation in design. This task should be collaborated with the Robotics Program to permit remotization of the proper apparatus. The demonstrations will involve test plans and final analysis reports, and eommercially available equipment.

Title:

TTP Number: Guidance:

Title:

TTP Number:

Guidance:

Title:

TTP Number:

Joint Participants:

Objective:

Title:

TTP Number: Joint Participants: Guidance:
Contamination Control

ID-121210

Complete the Rapid Transuranic Monitoring Unit and the Contamination Control Unit started in FY-92. Thesc units will be fabricated, performance tested, documented, and ficld tested in conjunction with the RES, RCS BWID retricval demonstrations during FY-93.

Fixation of Soil Surlaces

RL-430T10

Complete development and demonstration of a method that controls the wind transport of contaminated soil from excavation and clean-up sites. Focus on natural polysaccharides. These techniques will be labricated, performance tested, documented and lield tested in conjunction with the RES, RCS BWID retrieval demonstrations during FY-93.

Graphitc DC Arc Plasma

RL321211

Industry, Universitics

The primary objective of this task is the development of a novel DC graphite electrode plasma lorch and lurnace for the treatment of a variety of waste types including solids, liquids, and off-gas streams. A collaborative effort between Pacific Northwest Laboratory (PNL), Massachusetts Institute of Technology (MIT), and Electro-pyrolysis, Inc., (EPI) was initiated in FY-92 to accomplish this task. In FY-92, the lirst phase of testing was initiated in the Mark I DC are plasma lurnace at the MIT Plasma Fusion Center. FY-93 will complete testing of Mark I lurnace and will initiate testing of the Mark II system.

\section{BWID Arc Melter Vitrification}

ID-132011

Industry

The purpose of this project is 10 demonstrate, in a currently operational small commercial sicale arc melter (2-m high, 1.3-m diameter, 1-2 MVA, 1-2 ton/h), the applicability of existing are melter process technology to the treatment of mixed transuranic contaminated wastes and soils (buried or stored) at the INEL and other U.S. Department of Energy (DOE) sites. Demonstration testing of the vitrification of matcrials representative of incinerated waste and 
contaminated soils trom INEL and potentially other DOE sites is proposed to be performed in an existing arc melter furnace test facility at the U.S. Bureau of Mines (BOM). This is a natural extension of an American Society of Mechanical Engineers commercial incinerator waste ash vitrification demonstration project presently ongoing at the BOM. 


\section{Appendix B}

\section{BWID Secondary System Technologies}


.

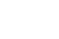




\section{Appendix B}

\section{BWID Secondary System Technologies}

Title:

TTP Number:

Joint Participants:

Guidance:

ID/IP:

Title:

TTP Number:

Guidance:

ID/IP:

Title:

TTP Number:

Guidance:

ID/IP:

Title:

TTP Number:

Guidance:
Thermal Kinetics

ID-132010

Industry

Vitrification (ex situ and in situ) is being considered as a potential remedial technology for treatment of buried wastes. The resultant waste form has been shown to be extremely durable and leach resistance. Vitrification is particularly effective for the treatment of toxic metals and radionuclides. Unlike organic and other inorganic contaminants, metals cannot be destroyed. Therefore, the ability of the vitrification waste form to immobilize these hazardous elements is very important in reducing the exposure potential to the environment. This effort will investigate the transuranic releases that occur as a result of vapor/liquid transport phenomena during in situ vitrification.

In Situ Remediation IP (ISRIP)

Chemically Enhanced Barriers/Vadose Zone

RL331002

Optimize the effectiveness of (a) hydraulic and diffusion barriers and (b) permeable barriers to be used in vadoxe or aquifer sediments to minimize contaminant migration. Concentrate on developing chemical reagent/barriers that minimize movement of chlorinated hydrocarbon solvents and mobile inorganic regulated metals/radionuclides.

\section{Characterization \& Sensor Technology Development IP (CSTDIP)}

Parsons Superfund Site: ISV Data Collection

RL331001

Collect full-scale operational and performance data during FY-93 in situ vitrification remedial operations conducted at the Parsons Superfund Site in Lansing, Michigan. Data to be collected includes heat flux data, moisture profiles, soil permeability, transport measurements of inert species, and mass balance of mercury and pesticides adjacent to the melt.

Mixed Waste Landfill ID (MWLID)

In-situ Determination of Radionuclide and Metal Contaminant Concentrations RL-321113

An in situ sensor capable of measuring both radioactive and stable metal contaminants in and around a landfill will be designed and fabricated. Radioactive contaminants will be determined by measuring their gamma ray emissions with a small intrinsic germanium diode gamma-ray spectrometer. 
ID/IP:

Title:

TTP Number:

Guidance:

\section{MWLID}

In-situ Containment and Stabilization of Buried Waste

CH-321101

Optimize grout-soil compositions and emplacement technologies for the soils and wastes present at the Sandia Chemical Waste Landfill. Perform bench-scale tests of in situ stabilization methods and characterize the physical and chemical properties of the stabilized mass. 
Appendix C

BWID Research and Development Technologies 


$$
\text { C-2 }
$$




\section{Appendix C}

\section{BWID Research and Development Technologies}

Title:

TTP Number:

Joint Participants:

Guidance:

Title:

TTP Number:

Joint Participants:

Guidance:

Title:

TTP Number:

Joint Participants:

Guidance:

Title:

TTP Number:

Joint Participants:

Guidance:
Dig Face Characterization

ID-132003

Characterization Integrated Program (IP), Robotic Technologies IP, Industry, Universities

Design and build a first generation characterization system to collect detailed, multisensor characterization data on an active remediation dig face, and use the data to detect and identify buried hazards as they are exposed by excavation. Coordinate this Buried Waste Integrated Demonstration (BWID) effort with the characterization integrated program and the robotics integrated program.

\section{Retrieval Technologies}

ID-132007

Industry

Complete development of the electrostatic enclosure curtain initiated in FY-92. Performance testing will take glove box scale data and expand to engineering scale so that the technology can be passed to EM-30 and 40 in FY-94.

Multiaxis Crane Control System

ID-332002

Robotic Technologies IP, Industry

Complete an evaluation of the Multiaxis Crane Control System acquired by BWID in the cryogenic retrieval demonstration of FY-92. Complete a demonstration of an enhanced controlled crane system and initiate technology transfers. Based on this demonstration and associated documentation, a final recommendation of status relative to EM-30 and 40 needs will be given.

Final Waste Form Integration and Limits

ID-132006

Mixed Waste IP, Industry

Provide for the integration in the following areas of BWID evaluations of pretreatment and treatment technologies: standard waste form compositions, required Idaho National Engineering Laboratory (INEL) soil for testing, establish and issue waste form performance requirements, technology testing and evaluation, and configuration option (system) interfaces and requirements. Integration with the other activities such as the use of waste from retrieval evaluation will also be facilitated. This work will also include participating in the American Society for Testing and Materials activities on developing standards for storage, treatment, and disposal of mixed waste. 
Title:

Thermal Kinetics

TTP Number:

ID-132010

Joint Participants: Industry

Guidance:

ID/IP:

Title:

TTP Number:

Vitrification (ex situ and in situ) is being considered as a potential remedial technology for treatment of buried wastes. The resultant waste form has been shown to be extremely durable and leach resistance. Vitrification is particularly effective for the treatment of toxic metals and radionuclides. Unlike organic and other inorganic contaminants, metals cannot be destroyed. Therefore, the ability of the vitrilication waste form to immobilize these hazardous elements is very important in reducing the exposure potential to the environment. This effort will identify ex situ vitrification technical issues facing technology application to buried waste forms.

Guidance:

ID/IP:

Title:

TTP Number:

Characterization and Sensor Technology Development IP (CSTDIP) Nonintrusive Sitc Characterization

AL111104

Form an interagency working group to plan and monitor a coordinated program of demonstrations involving Integrated Space, Airborne, and Surface remote sensing and noninvasive geophysical methods.

Guidance:

ID/IP:

Title:

TTP Number:

CSTDIP

Remote Sensing Systems

NV001102

The focus of this project is the coordinated development and evaluation of existing sensor systems and new remote sensing technologies for environmental restoration and waste management applications. Existing remote sensing systems and their associated processing techniques will be evaluated and optimized to address sitc characterization and monitoring needs.

Guidance:

Underground Storagc Tank ID (USTID)

Early Deployment System

RL332001

Develop and deploy a remotc characterization system that includes (a) the remote insertion of a sensor package that can assay waste tank gas contents, (b) perform nonintrusive mapping of the waste using laser-range finding, and

(c) conducting a topological survey of the waste surlace using structured lighting.

ID/IP: $\quad$ Mixed Waste IP (MWIP)

Title: $\quad$ CH3320(1

TTP Number: Waste Form Perlormance Criteria

Guidance:

Provide a standard for performing waste form property and performance testing with a vicw toward long-term predictability of waste form behavior. Develop a generalized methodology for the purpose of standarizing test methods for mixed waste throughout the DOE complex. 
ID/IP:

Title:

TTP Number: Guidance:

\section{Mixed Waste IP (MWIP)}

PE021202

Plasma Hearth Process

Conduct tests using surrogate waste that is representative of the DOE complex mixed low-level waste streams. Provide data required to determine if enhanced waste form production will improve life-cycle costs over baseline technology and waste forms. 


\section{Appendix D}

\section{BWID Participants and Responsibilities}




\section{Appendix D}

\section{BWID Participants and Responsibilities}

\section{D.1 Office of Technology Development Burled Waste Integrated Demonstration Program Manager}

The Office of Technology Development (OTD) (EM-50) Buried Waste Integrated Demonstration (BWID) Program Manager will provide programmatic guidance, establish overall technical and schedule objectives, allocate funding, define key milestones, recommend strategies, approve plans, and monitor progress toward achievement of programmatic objectives.

\section{D.2 Idaho National Engineering Laboratory Technical Program Officer}

The Idaho National Engineering Laboratory Technical Program Office (TPO) will be the focal point for all technical and financial administration conducted by BWID. The TPO will provide the day-to-day point of contact with the U.S. Department of Energy (DOE) Headquarters, maintain line management accountability and responsibility to DOE Idaho Field Office, and provide guidance and direction to the Integrated Demonstration Coordinator (IDC).

\section{D.3 Integrated Demonstration Coordinator}

The IDC will function as the primary focal point for all contacts and correspondence relative to BWID. The IDC is responsible for ensuring that the BWID programmatic objectives are achieved. The IDC will recommend technologies and projects to the TPO for inclusion in BWID. The IDC will coordinate technology evaluations and programmatic direction with the assistance of the Program Planning Group (PPG) and Technical Support Groups (TSG). The IDC shall also function as the principal interface with other OTD sponsored Integrated Demonstrations or Integrated Programs. The IDC is the primary focal point for all participating organizations who demonstrate technologies under BWID. The IDC is responsible for monitoring technical progress, as well as cost and schedule performance of all participating organizations in accordance with established TTPs. The IDC is responsible for ensuring that all relevant regulatory requirements are met and tracking BWID schedules to facilitate compliance.

\section{D.4 Program Planning Group}

Collaboration with other sites in the DOE complex will be facilitated through the PPG. The PPG will continually evaluate BWID programmatic direction against the Environmental Restoration and Waste Management (ERWM) needs of the entire DOE complex. The PPG will provide input on ERWM needs to the IDC. The PPG will review technical recommendations of the IDC and TSGs to ensure consistency with program objectives. The PPG will review recommendations for funding, technology selection, technical direction, and analysis and evaluation of test results. The PPG will facilitate technology transfer throughout the DOE complex. 


\section{D.5 Technical Support Groups}

The BWID TSGs will consist ol technology development experts representing specific areas of expertise pertinent to BWID activities. TSG personnel will be drawn from organizations throughout the DOE complex, private industry, academic community, and other Federal agencies. The TSGs will provide the technical expertise to screen, evaluate, and status proposed and BWID-sponsored technologies. 


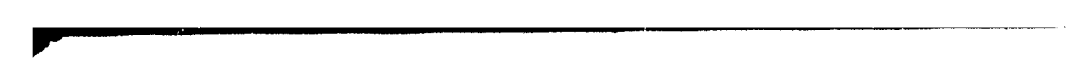

$\nabla$
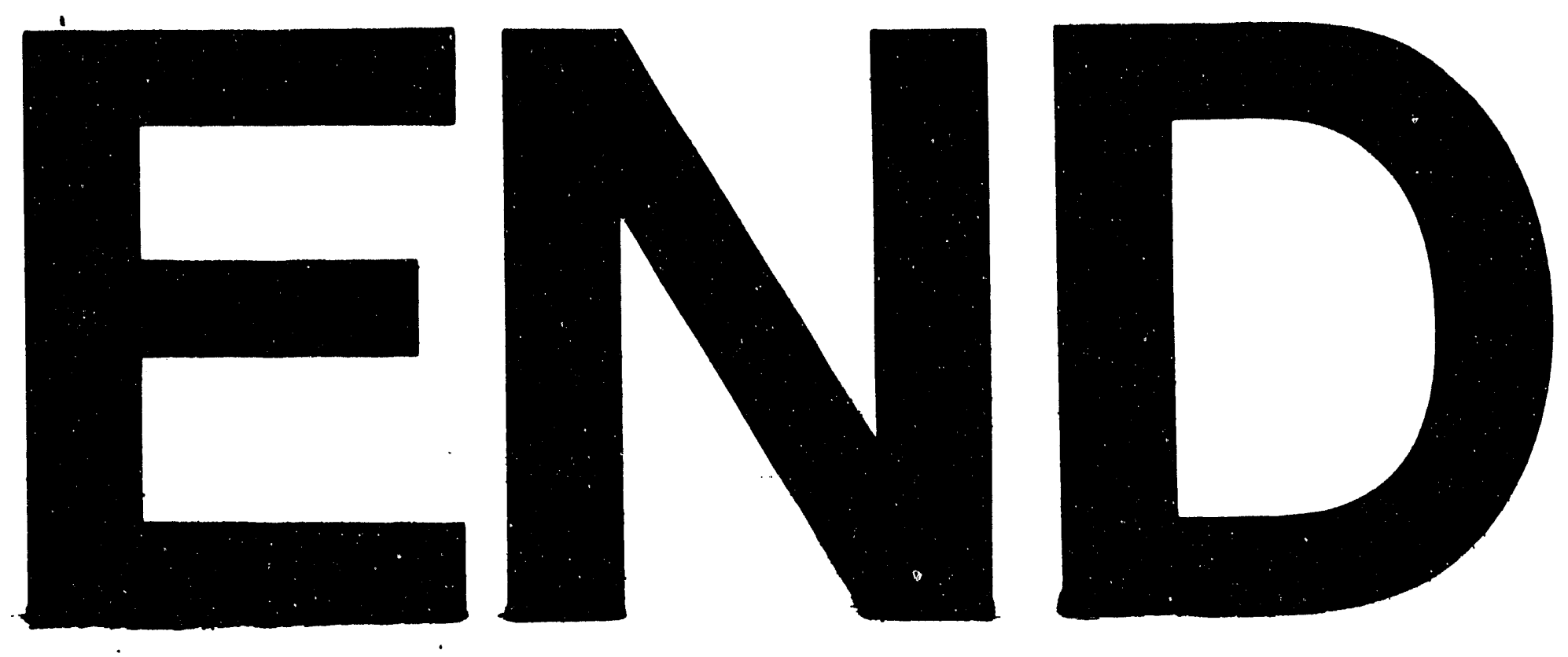

Fa
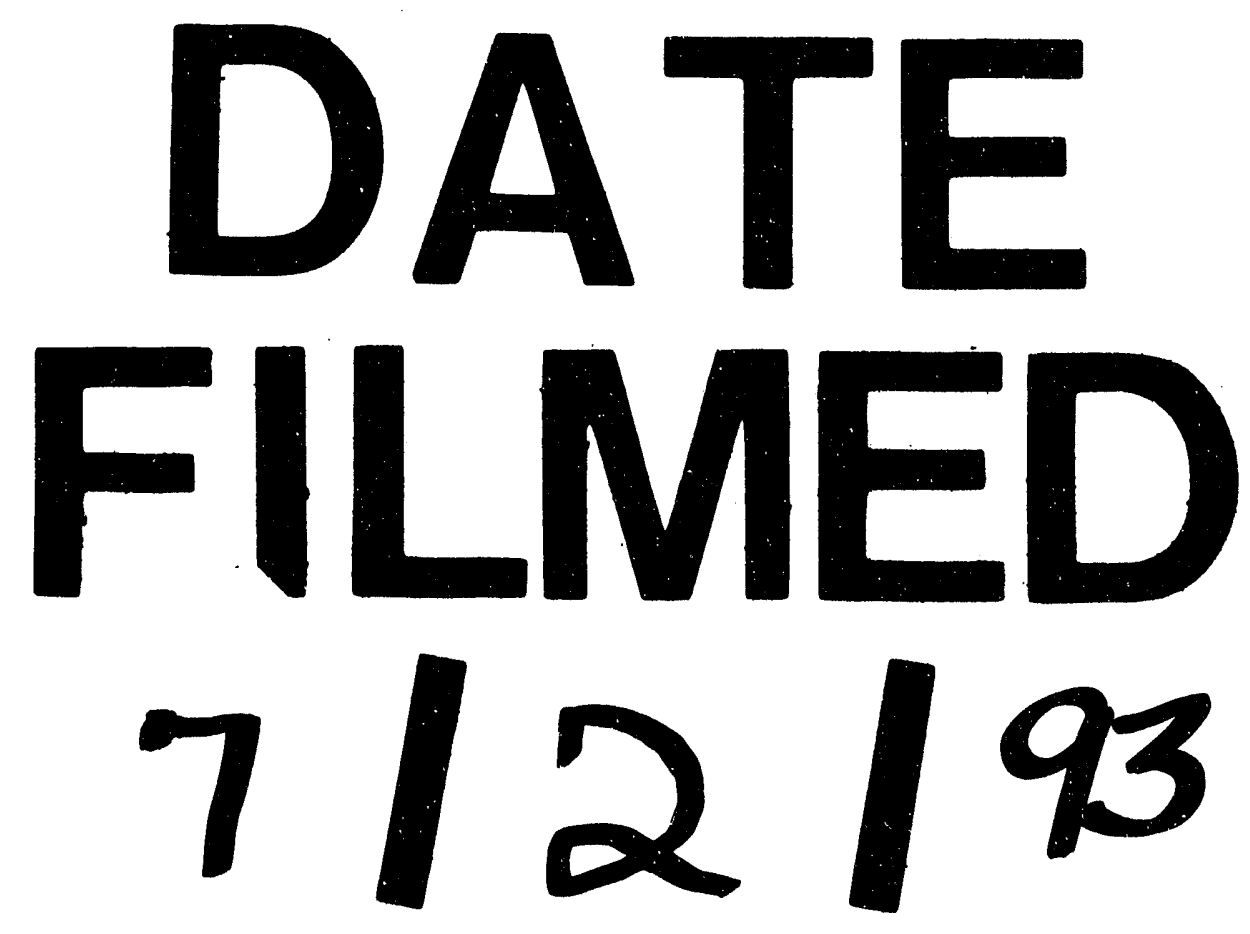

三 
